\title{
An Analysis with Rotter Internal-External Locus of Control Scale, Rosenberg Self-Esteem Scale, and the Barratt Impulsivity Scale on Patients Who Attempted to Recurrent Suicide
}

\author{
Irfan Aydin' (D), Abdullah Algin' (D), Mehmet Kaan Poyraz (D), Aysun Kalenderoglu² (D) \\ 'Department of Emergency Medicine, Adiyaman University Training and Research Hospital, Adiyaman, Turkey \\ 2Department of Psychiatry, Adiyaman University Training and Research Hospital, Adiyaman, Turkey
}

Cite this article as: Aydin I, Algin A, Poyraz MK, Kalenderoglu A. An Analysis with Rotter Internal-External Locus of Control Scale, Rosenberg Self-Esteem Scale, and the Barratt Impulsivity Scale on Patients Who Attempted to Recurrent Suicide. Eurasian J Emerg Med. 2018; 17 (3): 109-12.

\begin{abstract}
Aim: This study was actualized in order to see whether the patients who applied to the emergency service based on suicide would repeat this situation, to overtake again also to take necessary precautions.

Materials and Methods: A total of 910 folders of patients who were admitted to Adiyaman University Medical Faculty Education and Research Hospital Emergency Service with suicide attempt between January 1, 2012, and December 31, 2014, were evaluated retrospectively. Eventually 148 patients with recurrent suicide attempts were reached. Fifty-two patients voluntarily participated in the study. Rotter internal-external locus of control scale, Rosenberg self-esteem scale and the Barratt impulsiveness scale tests were applied to those patients. As a control group, 51 patients who attempted suicide once and 45 healthy subjects who were never involved in suicide attempts were included in the study.

Results: There was no difference between the groups in terms of age and sex. According to the Rotter scale, both groups attempting suicide were found to be more external-focused than the group without any suicide attempts. On the contrary, there is no difference among those attempting suicide. According to Barratt impulsiveness scale scores, patients who attempted suicide once were more impulsive than patients who attempted suicide recurrently.

Conclusion: Barratt impulsiveness scale and Rosenberg self-esteem scale can be used to evaluate the risk of recurrent suicide attempts in patients who has single suicide attempted. Since the Rotter scale can make a distinction between healthy individuals and those who attempt suicide, it can be used for screening in high-risk groups for suicide attempts, especially for adolescents.
\end{abstract}

Keywords: Barratt, rotter, rosenberg, suicide

\section{Introduction}

Suicide is an attempt to put an end to a person's life voluntarily. It is a form of aggression directed at a person's self (1). According to the World Health Organization (WHO), 2\% of the deaths are caused by suicides, and more than one million people commit suicide every year (2). Suicide rates vary between $0.003 \%$ and $0.045 \%$, and especially among young people, it is one of the leading causes of death follow- ing traffic accidents. It is also ranked second in the causes of injury (3). Therefore, suicide must be considered as a public health problem.

One of the most important predictors for a suicide attempt is the presence of previous suicide attempts. For this reason, one of the approaches to prevent suicide is to identify the risk for recurrence suicide after first suicide attempt (4). If it is possible to investigate socio-demographic data to determine individuals with high recurrence

ORCID IDs of the authors: I.A. 0000-0003-0136-3930; A.A. 0000-0002-9016-9701; M.K.P. 0000-0003-1579-4045; A.K. 0000-0002-8216-8610. 
risk using various scales for the suicide patients who applied emergency services, then completed suicide attempts may be prevented by conducting more intense psychiatric help for those patients. For this reason, it is vital to determine scales that guess recurrence for patients who had attempted first suicide.

The impulsive act is defined as "a cognitive function where an individual does not thoroughly think before giving a response or start a task" (5). Impulsive suicide attempts are more common especially in young people, and it is also stated to be more common in women than in men (6). Anger and aggressive behavior are treated as significant risk factors for suicidal behavior. Studies that show the relationship between aggression, impulsive behavior, and suicide attempts are frequently encountered (7).

The concept of locus of control is based on the belief whether there will be a rein forcer coming after an individual's behavior. If someone believes that those rein forcers are under the control of their own behavior, it is accepted as internal locus of control; however, if $s /$ he thinks they are under the control of luck or other powers, then it is considered to have external locus of control (8). Many studies indicate that suicide attempts are more common with in individuals who have external locus of control (9).

Self-esteem, in the broadest sense, reflects a person's evaluation of their own as valuable, effective, and successful (10). Feeling of self-worthy; ability to reveal their skills, abilities and knowledge; boasting of achievements, acceptance within the community, accepting and embracing their own bodily characteristic; and having own self-esteem are the leading factors in the formation and development of self-esteem (11). Low self-esteem has been reported to be associated with self-harm and suicide attempts (12).

In this study, we investigate the predictability of the risk of recurrence for the individuals who had recurrent and non-recurring suicidal attempts with using the Barratt impulsivity scale (BIS), the Rotter internal-external locus of control scale (RIELCS), and the Rosenberg self-esteem scale (RSS).

\section{Materials and Methods}

\section{Sample}

In this study, 910 patients who attempted suicide had been taken to the emergency service at the Department of the Medical Faculty of Adiyaman University Educational and Research Hospital between January 1, 2012 and December 31, 2014. The patients who had attempted suicide in 2012, before or following 3 years, were accepted as recurrent suicide attempts. These patients were called and invited to the hospital for interview. Patients who did not sign the patient consent form and also who died were not included in the study. The control group consisted of volunteers who were healthy. Ethics committee approval was obtained from Adiyaman University Faculty of Medicine Ethics Committee.

\section{Scales}

\section{Rosenberg self-esteem scale (RSS)}

Rosenberg self-esteem scale was developed by Rosenberg (1965) and adapted to Turkish; reliability and validity studies were carried out by Çuhadaroğlu in 1985. The scale has 12 sub-tests-one of which is self-esteem sub-test and is composed of 10 articles. In the self-esteem sub-test, it has been accepted that scores between 0 and 1 indicate high self-esteem, scores between 2 and 4 indicate average, and scores between 5 and 6 indicate low self-esteem (13).

\section{Rotter internal-external locus of control scale (RIELCS)}

In our country, the validity and reliability studies of RIELCS developed by Rotter have been made by Dag (1966) (14). This scale is composed of 29 double articles and aims to locate the individuals' generalized control expectations on internal-external locus. Each article contains two choices that are restricted to elective answering type. Six articles were placed as a filling in order to hide the aim of the scale and external aspects of choices of other 23 articles were evaluated as 1 point. Thus, scale scores show differences between 0 and 23, and higher scores point out increase in belief in external locus control $(15,16)$.

\section{Barratt impulsiveness scale (BIS)}

The scale, developed by Barrat et al. (17), is a self-report measure composed of 30 articles (16). Higher scores point out to higher impulsiveness levels. Validity and reliability studies of the scale have been carried out.

\section{Statistical analysis}

Data have been evaluated by IBM Statistical Package for the Social Sciences version 21.0 (IBM SPSS Corp.; Armonk, NY, USA). Frequency and percentage have been used for categorical variables as descriptive statistics, and mean and standard deviation have been used for continuous variables. Chi-square test has been used for comparing categorical variables among groups. Kolmogorov-Smirnov test was used to evaluate whether continuous variables meet the parameters of normal distribution. Kolmogorov-Smirnov test was used to evaluate whether continuous variables meet the parameters of normal distribution. Independent two-samples t-test was used for parameters fitting normal distribution in comparing among groups of continuous variables, and Mann-Whitney $U$ test was used for parameters not fitting normal distribution. ANOVA test was applied for parameters fitting normal distribution in comparing among three groups of continuous variables, and Kruskal-Wallis test was applied for parameters not fitting normal distribution. $\mathrm{p}<0.05$ was accepted as statistically significant level.

\section{Results}

In the scanning of the folders, 148 recurrent suicide attempted patients were detected. Of these patients, 114 were female, 89 patients were single $(60.1 \%), 80$ patients were primary school graduate (54.1\%), and 59 patients were unemployed. At most, there were patients who were in the age group of $15-24$ y $(s=94,63.5 \%)$. A total of 129 patients took medicine and toxic substance as a way of suicide attempt. The most frequent cause of suicide was reported as familial problems ( $s=41,27.7 \%) ; 88$ (59.5\%) patients had psychiatric diagnoses and $64(43.2 \%)$ patients had psychiatric treatment in the last six months.

After scanning of the patient folders, they were called and invited to the hospitals for interview. Fifty-one single suicide attempted patients, 52 recurrent suicide patients, and 45 control patients who 
have never attempted are included in the study. Sociodemographic data of the three groups are presented in Table 1. There was not any significant difference among groups in terms of age and sex $(p=0.216$ and $p=0.297$, respectively). However, it has been understood that the control group has a higher level of education, and they are mostly employed (for each $\mathrm{p}<0.001$ ).

Average RIELCS scores of single attempted and recurrent patients were not different $(p=0.677)$ but they were lower in control groups $(p<0.001)$. While the BIS scores of single suicide attempted patients were higher than recurrent patients $(p<0.001)$, there were no difference between all attempters and control group. Average RSS score was the highest in recurrent suicide attempts in single attempts and were significantly lower than them $(p=0.023)$, and when compared, control groups were significantly lower in all attempted patients $(p<0.001)$ (Table 2).

\section{Discussion}

It has been detected in studies including psychologic autopsy that nearly $44 \%$ of deaths in completed suicides attempted suicide before (18). In the study carried out on 898 patients by Kir et al. (17), the rate of recurrent suicide attempts was found to be $4 \%(s=36)(19)$. In literature, it has been reported that $30 \%-60 \%$ of suicide attempters have attempted suicide earlier too (20). It may be expected that the rate of recurrent suicide attempts in our country is lower than Western countries just because the rate of suicide attempts is lower. In our study, the rate of recurrent suicide attempts has been found to be $16.2 \%(s=148)$. This rate which is closer to the rates in literature may represent the increasing rate of suicide and recurrent suicide attempts in our country in years.
In a study carried out in the Netherlands, it has been stated that the highest risk age group for recurrent suicide attempt is 25-49 y (21). In our study, this age group has been the second rank with $35.8 \%$ rate. The age group of $15-24 \mathrm{y}$ has been the first rank with $63.5 \%$ rate. Our study shows us suicide attempts in children and adolescents has been increasing recently.

It is widely accepted that individuals who believe the resulting outcome of an event is linked to their own effort, own behavior are internally controlled and individuals who believe that outcome is linked to luck, fate, or powerful people are externally controlled according to the concept of locus of control (22). In most of the previous studies, depression and suicide attempts were found more often in individuals with external locus of control (23). Similar to literature, in our study, it has been determined that suicide attempters are more external locus than the control group. However, there is no difference between recurrent suicide attempters and single suicide attempters. According to these results, RIELCS can be used in general society scans and to determine the risk of suicide particularly risky groups such as adolescents, but this is not a suitable tool to determine the risk of recurrent attempts for single attempters.

Impulsivity includes a variety of behaviors that are unsuitable to condition, overly risky, not well-planned, and generally lead to undesirable consequences. Impulsivity is manifested by some features such as carelessness, headiness, neophilia, risk taking, pursuit of excitement and pleasure, low probability of damage, and extraversion (24).

Impulsiveness can be identified as a tendency to act thinking less than individuals with similar talent and knowledge, act without thinking enough and act quickly without deciding consciously or

Table 1. Sociodemographic features of recurrent suicide attempted patients or single suicide attempted patients and control groups

\begin{tabular}{|c|c|c|c|c|c|}
\hline & & $\begin{array}{c}\text { Single suicide } \\
\text { attempt }\end{array}$ & $\begin{array}{c}\text { Recurrent } \\
\text { suicide attempt }\end{array}$ & $\begin{array}{c}\text { No suicide } \\
\text { attempt }\end{array}$ & $\mathbf{p}$ \\
\hline \multirow{2}{*}{ Sex } & Female $(n, \%)$ & $36(70.6)$ & $37(71.2)$ & $26(57.8)$ & \multirow{2}{*}{0.297} \\
\hline & Male $(n, \%)$ & $15(29.4)$ & $15(28.8)$ & $19(42.2)$ & \\
\hline Age & Avarege (SS) & $29.26(8.91)$ & $26.47(8.44)$ & $26.85(8.49$ & 0.216 \\
\hline Education period & Year (SS) & $10.27(3.77)$ & $10.12(2.57$ & $13.69(3.13)$ & $<0.001$ \\
\hline \multirow{2}{*}{ Employment status } & Employed (Number, \%) & $8(15.7)$ & 9 (17.6) & $24(53.3)$ & \multirow{2}{*}{$<0.001$} \\
\hline & Unemployed (Number \%) & $43(84.3)$ & $42(82.4)$ & $21(46.7)$ & \\
\hline
\end{tabular}

Table 2. Comparison of scores of Rotter Internal-External Locus of Control Scale, Rosenberg Self-esteem Scale, and The Barratt Impulsivity Scale in recurrent suicide attempted patients or single suicide attempted patients and control groups

\begin{tabular}{|l|c|c|c|c|c|}
\hline & \multicolumn{1}{|c|}{$\begin{array}{c}\text { Single } \\
\text { suicide } \\
\text { attempt } \\
\text { (mean) }\end{array}$} & $\begin{array}{c}\text { Recurrent } \\
\text { suicide } \\
\text { attempt } \\
\text { (mean) }\end{array}$ & $\begin{array}{c}\text { (Comparing groups } \\
\text { attemples patients } \\
\text { with recurrent suicide } \\
\text { attempted patients) } \\
\text { (mean) }\end{array}$ & $\begin{array}{c}\text { Control } \\
\text { groups } \\
\text { (mean) }\end{array}$ & $\begin{array}{c}\text { (Comparing } \\
\text { the suicide } \\
\text { attempted groups } \\
\text { with control groups }\end{array}$ \\
\hline $\begin{array}{l}\text { Rotter Internal-External Locus of } \\
\text { Control Scale (average SS) }\end{array}$ & $13.45 \pm 2.91)$ & $13.72( \pm 3.54)$ & 0.677 & $10.61( \pm 3.21)$ & $<0.001$ \\
\hline Barratt Impulsiveness Scale (average SS) & $67.24( \pm 7.90)$ & $60.25( \pm 10.73)$ & $<0.001$ & $63.86( \pm 7.77)$ & 0.927 \\
\hline Rosenberg Self-esteem Scale (average SS) & $2.07( \pm 1.04)$ & $2.55( \pm 1.04)$ & 0.023 & $1.20( \pm 0.62)$ & $<0.001$ \\
\hline
\end{tabular}


without thinking ahead. Impulsiveness is an important concept for many psychiatric disorders especially attention deficit and hyperactivity disorder. The relationship between impulsiveness and suicide attempts has frequently been reported before. It has been reported that suicide attempts carrying features of impulsiveness are seen mostly among teenagers and women (25). In a study carried out with suicide attempters and non-attempters, it has been determined that impulsiveness scores of patients suffering from depression lowers in both groups after treatment, but impulsiveness scores were found to be higher in suicide attempters group both before and after treatment (26). Researchers commented on this situation as impulsiveness is a state and constant feature. According to the BIS, we could not find any difference between suicide attempters and control groups. However, impulsiveness scores were higher in single suicide attempters. So, we think that first suicide attempt can carry impulsive features, but non-impulsive planned suicide attempts are more risky for recurrent attempts.

It has been reported previously in many studies that low self-esteem increases the risk of suicide in adolescents and young adults $(25,26)$. We found that recurrent suicide attempters have the lowest self-esteem, single attempters have a significantly higher self-esteem than them and control group has the highest self-esteem. This situation makes us think that RIELCS can be used to foresee the risk of recurrent suicide both in general population and in single suicide attempters.

\section{Study limitations}

In our study, also the number of cases shows statistically significant results, we need to increase the number of cases to obtain a stronger result. Multi-center studies can be done to increase number of cases. Because the patients' contact addresses were wrong and some patients refused to participate in the study, 52 of 148 patients could be taken to study.

\section{Conclusion}

As a result, the first place to apply for patients who attempt suicide is the Emergency Service. Patients who underwent initial treatment are evaluated by psychiatry after the clinical condition has been corrected. With this study, these tests can also be done during adolescence to prevent suicide attempts and necessary precautions can be taken in advance. We believe that these tests will help us determine the risk of recurrence for those who are attempting suicide for the first time both in emergency services and during a psychiatric consultation.

Ethics Committee Approval: Ethics committee approval was received for this study from the Ethics Committee of Adiyaman University (Date: 16.06.2015, Number: 05-11).

Informed Consent: Patients/the parents of the patients who participated in this study confirmed the written approval form.

Peer-review: Externally peer-reviewed.

Author Contributions: Concept - A.K.; Design - M.K.P.; Supervision - I.A.; Resources - A.A.; Materials - I.A., A.A.; Data Collection and/or Processing - I.A., A.A.; Analysis and/or Interpretation - A.A., I.A., M.K.P.; Literature Search - A.A., I.A.;Writing Manuscript - A.A., I.A.; Critical Review - I.A., A.A.; Other -A.A., I.A., M.K.P., A.K.

Conflict of Interest: The authors have no conflict of interest to declare.
Financial Disclosure: The authors declared that this study has received no financial support.

\section{References}

1. Sayıl I, Berksun OE, Palabıyıkooglu R. Suicidal Behavior: Crisis and Crime Intervention. Ankara University, Research Center Publications, Damla Printing Press, 2000, Ankara, Turkey.

2. Bondy B, Buettner A, Zill P. Genetics of suicide. Mol Psychiatry. 2006; 11 : 336-51. [CrossRef]

3. Altındağ A, Sır A, Özkan M. Suicide attempt and its relationships with clinical features and sociodemographic variables in psychiatric patients. JMOOD. 2014; 4: 2 .

4. Williams CL, Davidson JA, Montgomery I. Impulsivesuicidal behavior. J Clin Psychol. 1980; 36: 90-4. [CrossRef]

5. Michaelis BH, Goldberg JF, Davis GP, Singer TM, Garno JL, Wenze S. Dimensions of impulsivity and aggression associated with suicide attempts among bipolar patients: A preliminary study. Suicide Life Threat Behav. 2004; 34: 172-7. [CrossRef]

6. Zouk H, Tousignant M, SeguinM, Lesage A, Turecki G. Characterization of impulsivity in suicide completers: Clinical, behavioral and psychosocial dimensions. J Affect Disord. 2006; 92: 195-204. [CrossRef]

7. Liu X, Tein JY, Zhao Z, Sandler IN. Suicidality and correlates among rural adolescents of China. J Adolesc Health. 2005; 37: 443-51. [CrossRef]

8. Özkan I. Factors Affecting Respect for Self. Journal of Thinking Man. 1994, 7: 4-9.

9. Cotton NS. A developmental model of self-esteem regulation. Flach F (editör). Stress and Its Management. New York: Norton, 1985.s.37-57.

10. Akdemir D, Zeki A, Yetimoglu Unal D, Kara M, Cuhadaroglu Cetin F. Identity Status and self-esteem in adolescents with non-suicidal self-injurious behavior. Anatol J Psychiatry. 2013; 14:69-76. [CrossRef]

11. Rosenberg M. Society and the adolescent self-image. Princeton, NJ: Princeton University Press, 1965. [CrossRef]

12. Cuhadaroglu F. A research on self-esteem in Turkey. XXI. National Congress of Psychiatry and Neurology, 1985, Mersin, Turkey.

13. Oner N. Examples of Psychological Testing Used in Turkey. Expanded second edition, Boğaziçi University Press, 2006, Istanbul, Turkey.

14. Moeller FG, Barratt ES, Dougherty DM, Scmitz JM, Swann AC. Psychiatric aspects of impulsivity. Am J Psychiatry. 2001; 158: 1783-93. [CrossRef]

15. Gulec H, Tamam L, Gulec MY, Turhan M, Karakus G, Zengin M, et al. Psychometric properties of the Turkish version of the Barratt Impulsiveness Scale-11. Bulletin of Clinical Psychopharmacology. 2008; 18: 251-8.

16. Can SS, Sayıl I. Recurrent Suicide. J Crisis. 2004; 12: 53-62.

17. Kir MZ, Gunduz E, Gullu MN, Uysal C, Korkmaz M, Icer M, et al. Recurrent suicide attempt cases in Diyarbakir, Turkey. Eur J Forensic Sci. 2014; 1: 9. [CrossRef]

18. Sakinofsky I. Repetition of suicidal behaviour. Hawton $\mathrm{K}$, van Heeringen $\mathrm{K}$ (Publisher). The International Handbook of Suicide and Attempted Suicide. Wiley, 2002, p.385-404.

19. Arensman E, Kerkhof JFM. Classification of attempted suicide: A review of empiricalstudies, 1963-1993. Suicide Life Threat Behav. 1996; 26: 46-67.

20. Ongen D. Validity and Reliability of The Locus of Control Scale. Journal of Educational Administration in Theory and Practice. 2003; 35: 436-47.

21. Beautrais Al, Joyce PR, Mulder RT. Personality traits and cognitive styles as risk factors for serioussuicide attempts among young people. Suicide Life Threat Behav. 1999; 29: 37-47.

22. Moeller FG, Barratt ES, Dougherty DM, Scmitz JM, Swann AC. Psychiatric aspects of impulsivity. Am J Psychiatry. 2001; 158: 1783-93. [CrossRef]

23. Conner KR, Meldrum S, Wieczorek WF, Duberstein PR, Welte JW. The Association of Irritability and Impulsivity with Suicida Ildeation Among 15 to 20 year Old Males. Suicide Life Threat Bahav. 2004; 34: 363-73. [CrossRef]

24. Ozdemir GP, Selvi Y, Aydın A. Impulsivity and Treatmant. Current Approaches in Psychiatry. 2012; 4: 293-314. [CrossRef]

25. Corruble E, Damy C, Guelfi JD. Impulsivity: A relevant dimension in depression regarding suicide attempts? J Affect Disord. 1999; 53: 211-5. [CrossRef]

26. Tomori M, Zalar B, Plesnicar BK. Gender differences in psychosocial risk factors among Slovenian adolescents. Adolescence. 2000; 35: 431-43. 